a very few stones, which had been reddened and crackled by fire. No trace of burnt wood, ashes, or bone could be seen. It was remarkable that nearly all the stones found were flakes, as very few unworked pieces of flint could be lighted on. The flakes from the huts differ in condition materially from the flakes in the fields below, as all the flakes in the fields are marked with dark ferruginous strains, whilst those from the hut-floors are perfectly unstained, no iron having ever reached them.

In the immediate neighbourhood $I$ have at different times found a large number of scapers, a lance-head, a few arrowheads, and a few rudely.chipped celts, some broken. One small chipped celt has incurved sides, indicating, as Mr. John Evans has pointed out in his work on stone implements, that this particular form was possibly an imitation in flint of an early, flat bronze celt.

It is always well to examine the earth brought out of holes by rabbits, moles, foxes, rats, and other animals, in places where prehistoric relics exist on pasture-land. I have secured a considerable number of my antiquities from such places.

Last year I told a young niece of mine to keep a watch on such places at the spot where the five large tumuli are placed on Dunstable Downs, and where I had on previous occasions found flint flakes in the heaps made by moles, \&c. It was not long before niy niece lighted on two pieces belonging to the back part of a human skull. They had been scratched out of the base of the northernmost tumulus by some animal. Fortunately the two pieces fitted together; they are evidently of great antiquity, and probably represent part of the person who was buried in the tumulus, quite possibly one of the old chippers of Neolithic implements.

WORTHINGTON G. SMITH

\section{A Lady Curator}

IN NATURE for November 27, 1884 (p. 90) you acknowledge the receipt of the "Catalogue of the Natural History Collections of the Albany Museum, Grahamstown, Cape of Good Hope," and allude to the "zealous curator." Are you aware that that individual is a young and accomplished lady? Here is another path opened for our daughters and "sweet girl graduates" to fame and fortune. Those who, like myself, have the pleasure and privilege of knowing and corresponding with Miss Glanville can appreciate the ardour and zeal with which she is following up her chosen vocation. May every success attend her.

British Consulate, Noumea, February 25

\section{Hoar Frost}

A Communication in Nature of January 8 (p. 216), in regard to frost-formations, leads me to send a word from Maine. I have seen frost-work so like the desiription there given, that it would answer very well for an account of frosts in this climate. These frost-formations occur when the wind is chilly and blowing steadlily, without the compass veering, for hours. I have compared these deposits to the most delicate designs of Oriental lace-work. At one time $I$ witnessed an accretion on a wall, where the feathery forms were from two to four inches in length, with the points towards the wind. I think this is because each added particle adhered to the very tip of the previous one. Certainly no pen-description can do justice to the delicate beauty when the sun suddenly broke through the clouds and shone upon this forest of frost-ferns.

CAROLINE W. D. Rich

Auburn, Me., A pril

\section{Rainbow Phenomenon}

ON Saturday night, about six o'cl ck, I observed, at old Trafford, on the west side of Manchester, a rainbow with accompanying phenomena, which I had never observed before. Several very heavy showers had occurred during the day. The wind was within a point or two of west. At the hour above named a cloud was passing over, very dense and uniform in rolour, and with that dark leaden hue so general in thunderstorms. There was, however, no thunder or lightning. Rain fell in torrents. As the cloud, which was of large area, passed off, the sun shone brightly in the north-west, and a magnificent rainbow painted itself on the dense black screen afforded by the cloud. The rainbow was double, the prismatic colours, of course, occurring in reverse order in the outer bow. The most remarkable feature of the display was the sharp contrast in the shadow of the cloud, evidently caused by the rainbow. Between the two bows it was of the densest leaden hue. Inside the inner bow it was exceedingly light coloured, with the faintest suggestion of luminosity. Outside the outer bow it was of an intermediate grey. The uniform mass of cloud was marked off by the two bows with geometrical accuracy into three regions, each perfectly homogeneous in itself, but distinctly contrasted with the two other tints. The effect was weird and startling, and was observed and commented upon by several spectators in whose company I was. There was another feature connected with the inner bow which $I$ have never observed before. The green and violet colours were repeated inside the bow. Probably the whole tract from green to violet inclusive was repeated, but I could only make out those two colours distinctly.

Have these peculiarities, either or both, been observed before, and, if so, how are they accounted for? CHARLES CROFT

Prestwich, near Manchester, May II

\section{FIVE MATHEMATICAL RARITIES}

A BRIEF reference to some recent reprints, \&c. by Dr. Bierens de Haan, of Leyden, may not be unacceptable, though, unfortunately, ignorance of the language in which four of them are written prevents our giving more than the barest description of them.

The "Stelkonstige Reeckening van den Regenboog," or Algebraical Calculation of the Rainbow, is a rare tract, by no less distinguished an author than $B$. de Spinoza. It was for a long time supposed to be lost, if not burned; it is here printed in exact facsimile from a copy published at the Hague in $\mathrm{I} 687$. Bound up with it is another rarity, similarly printed, entitled "Reeckening van Kanssen," or Calculation of Chances. No reference to this is made by Todhunter. There is a slight probability of this tract having proceeded from the same hand, as Dr. De Haan cites a reference to the forty-third letter in the collected works of Spinoza.

The third reprint is of a very rare book by A. Girard: "Invention nouvelle en l'Algèbre, tant pour la solution des équations, que pour recognoistre le nombre des solutions qu'elles reçoivent, avec plusieurs choses qui sont nécessaires à la perfection de ceste divine science" (Amsterdam, 1629). M. Marie writes : "Cet ouvrage est surtout remarquable par les idées justes que l'auteur émet au sujet des racines négatives des équations et de leur usage en géométrie."

The last two tracts have not been before printed : they are both the work of Simon Stevin, and are entitled "Van de Spiegeling der Singkonst" (i.e. Miroir de l'Art du Chant), and "Vande Molens." There is a full account prefixed to the former of these works, and we learn that the latter contains "le calcul de I9 moulins à vent, suivant la méthode usitée et suivant une nouvelle méthode de Simon Stevin lui-même, qui consiste à indiquer les roues, les dents et les pignons, afin de satisfaire à quelques conditions données."

Thanks are due to Dr. de Haan for the great care with which he has brought out these facsimiles, and we think he will certainly reap the reward he seeks. We quote his words in the last of these volumes: "J'ose esperer que la réproduction de ces ouvrages d'un homme si renommé pourra intéresser ceux qui s'occupent de l'histoire des sciences."

\section{ON CERTAIN SPECTRAL IMAGES PRODUCED BY A ROTATING VACUUM-TUBE}

$T H E$ beautiful effects produced by the rotation of a vacuum-tuhe when illuminated by a series of electrical discharges from an induction-coil are well known. The tube is generally attached to a horizontal axis, which is turned rapidly by means of a multiplying wheel; the images due to successive discharges which, if the tube were at rest, would be superposed, are thus caused to occupy different parts of the retina, and if the discharges 
follow one another at the rate of $n$ per second, the num ber of images simultaneously visible will be about $n / 8$ since the luminous image produced by each separate flash persists for about an eighth of a second after the flash itself has ceased. The result of these effects is the appearance of a gorgeous revolving star.

If the tube is made to rotate very slowly, there occurs a different and very curious phenomenon, which, so far as I know, has never hitherto been noticed. The tube used in my experiments was thirteen inches long, and contained various devices in uranium glass; the induction-coil had a resistance of $1400 \mathrm{ohm}$, and was worked by a single large bichromate cell. When the rotation is performed at about the rate of one turn in three seconds, the luminous images of the tube are almost superposed, forming a bunch which is slightly spread out at the ends. But about $40^{\circ}$ behind the bunch, and separated from it by an interval of darkness, comes a ghost. This ghost is in shape an exact reprnduction of the tube: it is very clearly defined, and distinctly shows every detail of the uranium glass devices. But the colour is entirely changed, the violet tint of the luminous bulb and the bright green fluorescence of the uranium glass being replaced by a uniform steel gray. If the rotation is stopped, the ghost still moves slowly on, and, after the lapse of about half a second, disappears in coalescing with the luminous tube. The phenomenon may be diagrammatically represented by the letter $X$, the thick stroke being the bunch of luminous images, and the thin stroke the spectral at tendant. The direction of the motion is supposed to be opposite to that of the hands of a watch when seen from above. If the rate of rotation is too slow, the ghost approaches the luminous bunch so closely as to be obscured by its superior brilliancy; while, if it is too fast, the image becomes blurred and ill-defined. The strength of the inducing current should be regulated by trial. With too strong a current the effect is the same as when the rotation is too slow; with too weak a current the image is rendered feeble. Generally speaking, the best results are obtained with a somewhat weak current.

The experiment has been witnessed by a dozen persons, all of whom, with the exception of one adult, and the doubtful exception of a child, at once saw the spectral image. It is almost ludicrously difficult for those who are able to see it, to understand how any one else could possibly fail to do so.

This curious effect clearly belongs to the class of spectral images or "ocular spectra," which result from looking at a bright object, persistence of vision in the ordinary sense of the term having nothing to do with it. I proved this to be the case in a very simple manner. The vacuum tube being at rest in a feebly-lighted room, $I$ concentrated my gaze upon a certain small portion of it while the discharge was passing. The current was then interrupted, and the luminous image was almost instantly replaced by a corresponding image which appeared to be intensely black upon a less dark background. After a period which I estimated at from a quarter to half a second (probably more nearly the latter), the black image again became luminous, assuming the characteristic steel gray colour: this luminous impression lasted but for a small fraction of a second, and the series of phenomena terminated with its disappearance. I found the effect to be most clearly marked when a narrow portion of the tube was observed; the definition of the spectral image was then exceedingly sharp, even the striæ being represented with perfect distinctness. It was also found desirable to make the preliminary illumination as short as possible, a single flash being generally sufficient to produce the phenomena. This is more easily effected by a judicious manipulation of the contact-breaker than by means of a key, or of the commutator attached to the coil. I may add that it is by no means certain that a person who is altogether new to the subiect will at first be able to see the appearances last described, even when he knows exactly what to expect. They belong to a class of phenomena which in ordinary life we habitually train ourselves to disregard, and our persistent neglect makes it difficult to perceive them when we desire to do so. With a little patient attention the difficulty will probably disappear. ${ }^{1}$ It was probably owing to my constant habit of studying visual impressions that the appearance of the ghost attracted my notice in the first instance.

The series of phenomena seem to be due to an affection of the optic nerve which is of an oscillatory character. Abnormal darkness follows as a reaction after the luminosity, and again after abnormal darkness there is a rebound into a feebler luminosity. Following this idea I have endeavoured to detect the existence of a second ghost as the result of a further rebound, but hitherto without success.

It is an interesting fact, as proved by these experiments, that the formation of a spectral image does not occur until the expiration of a measurable interval of time after the exciting cause has ceased to operate.

SHELFORD BIDWELL

\section{FUPITER}

DURING the present opposition of this planet, the details of the belts and spots have continued to furnish materials of great interest. Some very obvious modifications have occurred since the previous year, and several curious new features have become conspicuous. The great red spot has surprised us by its extended duration. As early as 1882 it lost such a considerable depth of tone that its obliteration seemed imminent, but it has lingered on, until now its existence appears likely to be indefinitely prolonged, though under visible conditions far less imposing than at an earlier stage. All that at present remains of this remarkable formation is a duaky elliptic ring, darkest at the following end, and only well seen under good definition. Whether this ellipse is identical with similar appearances delineated by Dawes in 1857 , Huggins in $185^{8}$, and Gledhill in 1869 , 1870, and 1871 is involved in doubt, because of the lack of intermediate observations. We have no definite information as to what became of the various objects alluded to. It is very possible that they severally represent an object of considerable permanency. The changes such as observed may have been induced by atmospheric interference. There is every indication that the dense vaporous envelopes of this planet are rapidly variable, especially in the zone included by the two equatorial belts, and that the chief features undergo singular fluctuations, some of which may possibly be of periodical character.

The particular objects drawn by Dawes and others suggest a close relationship to the red spot as it now appears. There is far from being an actual coincidence either in the positions or forms of the features here sought to be connected, but small differences must actually occur in results based on estimation. A sufficient likeness is established between them to show that further investigation may have an interesting outcome as affirming the theory of recurrent markings of identical form. There is, however, an inability to trace the history of these singular objects, owing to the meagre number of observations available. This is a circumstance much to be regretted. Markings of specially interesting character deserve something more than mere record. They should be persistently watched during several oppositions, if possible, for it is only by this continuity of records that the really important questions affecting them admit of settlement. The red

I The adult who failed to see the ghost is totally unable to perceive the subjective images in complementary colours, which generally result from gazing at brightly-coloured objects. Her general powers of vision are decidedly above the average and she is in no degree colour-blind. The doubtful child is a daughter of this adult. A younger child can certainl see the phenomenon. 